\title{
Influence of Standard and Modified Proctor Compactive Efforts on Cement Stabilized Black Cotton Soil (BCS) with Waste Glass (WG)Admixture
}

\author{
I.A.Ikara ${ }^{1} *$,A.M.Kundiri ${ }^{2}$ A.Mohammed ${ }^{1}$ \\ 1(Department of Civil Engineering, Abubakar Tafawa Balewa University, Bauchi State, Nigeria) \\ 2(Department of Civil and Water Resource Engineering, University of Maidugri, Borno State, Nigeria)
}

\begin{abstract}
A laboratory study on the influence of modified proctor $(M P)$ and standard proctor (SP) compactive effort on expansive black cotton soil (BCS) specimens treated with up to 8\% ordinary Portland cement (OPC) admixed with up to $20 \%$ waste glass (WG) by dry weight of soil were undertaken. The soil was classified as A-75(13) and CH according to the American Association of State Highway and Transport Officials (AASHTO) and the Unified Soil Classification System (USCS) Classifications. Chemical analysis revealed that WG is rich in main oxides such as Silicon Oxide (69.2\%), Aluminium Oxide (2.29\%), Iron Oxide (1.57\%), Calcium Oxide (15.1\%) and Sodium Oxide (8.75\%). The soil was stabilized with 0, 2, 4, 6 and 8\% cement and 0, 510,15 and $20 \%$ WG by weight of the dry soil. The results obtained showed an increase in maximum dry density (MDD) with increase in WG content in all cement proportions used and as compared to the values obtained for the natural soil. The tests showed significant effects of the additives. The peak 7 days unconfined compressive strength (UCS) values of $1152 \mathrm{kN} / \mathrm{m}^{2}$ and $1568 \mathrm{kN} / \mathrm{m}^{2}$ were obtained at $8 \%$ OPC / $20 \%$ WG treatment for the SP and MP compactive efforts, respectively. These values are lower than the $1720 \mathrm{kN} / \mathrm{m}^{2}$ recommended by Transport and Road Research Laboratory (TRRL) (1977) for adequate cement stabilization. The SP and MP compactive efforts at 28 days yielded UCS values of $1857 \mathrm{kN} / \mathrm{m}^{2}$ and $2005 \mathrm{kN} / \mathrm{m}^{2}$ which justified the slow pozzolanic reaction of WG when compared with cement hydration. CBR values were lower than the 180\% criterion recommended by the Nigerian General Specifications (1997) for cement stabilized soil, however, specimens treated with $8 \%$ OPC/ (5-20\%) WG and compacted at both energy levels met the requirement of $30 \%$ CBR specified by the Nigerian General Specification (1997) for sub-base in roads. Maximum improvement in CBR values of 55\% and $65 \%$ for the entire blend was archived at $8 \%$ OPC/20\%WG blend.
\end{abstract}

Keywords: Black cotton soil, Waste Glass, Ordinary Portland cement

\section{Introduction}

In recent years, research into applications of industrial waste material is continually being advanced, particularly concerning the feasibility, environmental suitability and performance of the beneficial reuse of these waste materials. In order to make soil useful and meet foundation engineering design requirements, since the cost of procuring materials that meet specification requirement are increasingly becoming uneconomical, research have been intensified with the aim of using admixtures/additives to reduce the cost of procuring cement for stabilization and other stabilizing agents. Various researchers, (Joel and Agbede, 2011; Moses and Osinubi, 2013; and Ashango and Patra, 2014), have attempted to stabilize soilso as to have a cost effective utilization of such soil and ensuring sustainability, particularly in regard to consumption of large material resources. The performance of these soils can be improved by improving its engineering properties by stabilization, which constitute one of the essential part of soil improvement techniques. Primarily, the objectives of soil stabilization are to improve the soil strength, decrease permeability and water absorption, improve soil bearing capacity and the durability under adverse weather condition.In addition,high compaction energy levels are normally used in soils in order to achieve the desired densification and strength improvement of soils. Thus, it is expected that increased compactive effort will produce an increase in strength of the soil. However, the behaviors of highly expansive clays do not follow the regular pattern of soils due to their mineralogical compositions. Black cotton soils (BCS) are clays that have a tendency for volume changes, to swell and soften or shrink and dry-crack, depending on the increase or decrease in moisture content.The swell-shrink movements in expansive soils affect the serviceability performance of lightweight structures supported on them. These soils increase in volume on absorbing water and decrease in volume when the water evaporates from them (Chen, 1988). The volume increase (swell) if resisted by any structure resting on it; then vertical swelling pressure is exerted by the soil on the structure. Due to this peculiar behaviour many civil engineering structures constructed on expansive soils get severely distressed. Pavements are in particular, susceptible to damage by expansive soils because they are lightweight and extend over large areas. It is therefore necessary to upgrade the engineering properties of deficient soils before they are put to use in construction.In this study, BCS is stabilized with OPC and waste 
glass admixture and compacted to two different energy levels. The unconfined compressive strength (UCS), California bearing ratio (CBR) and performance of stabilized soil are evaluated.

Glass is a hard material normally fragile and transparent common in our daily life. It is composed mainly of sand (silicate) and an alkali. It does not harm the environment in any way because it does not give off pollutants but it is non-biodegradable, once it is broken it can harm humans as well as animals if not dealt with carefully. It is regarded as useless and so discarded, littering the environment and constituting a nuisance in the community. The physical properties of the crushed glass are that they exhibit high permeability, high crushing resistance, small strain stiffness, and these properties could enhance its usage in geotechnical engineering works for soil stabilization, embankment constructions (Ikara et al, 2015).

\section{Materials And Methods}

Materials

The Black cotton soils used in the study was obtained from Baure villag in Yamaltu-Deba local government area of Gombe state, Nigeria. According to AASHTO Soil Classification System (AASHTO 1986), the soil is classified as A-7-5(13) and CH in the United Soil Classification System (ASTM 1992). The waste glass (WG) used was sourced from post-consumer waste.Chemical analyses were carried out at the National Steel Raw Material Exploration Agency (NSRMEA), Kaduna using X-ray fluorescence (XRF), to determine the oxide composition of the soil and WG. As shown in Table 1,

\section{Methodology}

Laboratory tests were conducted on both the natural and treated soils. Test for the natural soil was performed in accordance with the procedures outlined in BS 1377 (1990) and that of the stabilized soil was conducted in accordance to BS1924 (1990). Specifically, stabilization of the soil was done using Ordinary Portland cement (OPC) and WG as admixture.

Compaction Tests involving the moisture-density relationship, unconfined compression,shear strength and California bearing ratio were carried out at energies derived from the standard Proctor (SP) and modified Proctor (MP) energy levels. The moisture content density relationship for OPC/WG stabilized BCS mixture was determined at various percentages of cement $(0 \%, 2 \%, 4 \%, 6 \%$ and $8 \%)$ and waste glass $(0 \%, 5 \%, 10 \%, 15 \%$ and $20 \%$ ) by dry weight of the soil. The characteristics of these compactive efforts are shown in Table 3. The California Bearing Ratio (CBR) test were conducted on the BCS and OPC/WG stabilized BCS mixtures, the mixtures were compacted at their respective optimum moisture content in the CBR mould. Two set of each sample were prepared and subjected to un-soaked and soaked CBR test. The soaking was done for 48 hours.

The Unconfined Compression Test on BCS and OPC/WG stabilized BCS mixtures were compacted at optimum moisture content using the SP and MP energy levels respectively. Tests specimen are of specified height to diameter ratio in accordance with BS 1377. The cylindrical specimens used in this test are of diameter $38 \mathrm{~mm}$ and height $76 \mathrm{~mm}$. After compaction, the treated BCS and OPC/WG stabilized BCS was extruded from the mold and sealed with double wrappings in polythene bags that were kept in the humidity room at a constant temperature of $25 \pm 2{ }^{\circ} \mathrm{C}$. This was done for various periods to allow for uniform moisture distribution and curing. After curing, specimen were placed in a load frame machine driven strain controlled at $0.10 \% / \mathrm{min}$ and crushed until failure occurred. Specimens were cured for 7, 14 and 28 days.

\section{Index properties}

\section{Results And Discussion}

Preliminary tests were conducted for the identification and determination of the soil properties without the addition of OPC or WG admixture. The test results of natural soil is summarized in Table 2. Physical inspection showed that the soil is dark grey in color and an Activity of 3.06 which indicates that the soil is active. The high active value suggest montmorillonite clay mineral to be the dominant clay mineral. The Atterberg limit and sieve analysis tests classified the soil as A-7-5 and $\mathrm{CH}$ using the American Association of State Highway and Transportation Officials (AASHTO, 1986) soil classification system and Unified Soil Classification System (ASTM, 1992), respectively. These classifications showed that the soil is clayey soil of high plasticity. The liquid limit and plasticity index was observed to be of $65.5 \%$ and $30.6 \%$ confirmed that the soil is highly plastic. Atterberg limits results have been reportedly shown to be very useful indicators of soil behaviour (Jefferson and Rogers, 1998). The specific gravity of the soil was observed to be 2.65 which indicated the prevalence of montmorillonite, in conformity with Das (2005). The MDD values of $1.4 \mathrm{Mg} / \mathrm{m}^{3}, 1.51 \mathrm{Mg} / \mathrm{m}^{3}$ and $\mathrm{OMC}$ values of $25 \%, 19.8 \%$ for the standard proctor (SP) and modified proctor (MP) compactive energy obtained were in agreement with their findings. Free swell value of $75 \%$ indicated that the soil is of medium swell potential in accordance with NBRRI (1983). UCS values of $190 \mathrm{kN} / \mathrm{m}^{2}$ and $274 \mathrm{kN} / \mathrm{m}^{2}$ recorded for the natural soil at OMC for the two energy levels are relatively low. Similarly, low CBR values of $10.6 \%$ and $14 \%$ obtained at the energy levels of the SP and MP compaction further revealed that the material is not suitable for 
use as a construction material. This is in agreement with Nigerian General Specification (1997) and other researchers (Baraja, 1998: Osinubi, 1999).

Table 1: Oxide Composition of BCS and WG

\begin{tabular}{|l|l|l|}
\hline \multirow{2}{*}{ Oxide } & Concentration $(\%)$ & WG \\
\cline { 2 - 3 } & Soil & 2.29 \\
$\mathrm{~A} 2 \mathrm{O} 3$ & 16.58 & 69.2 \\
$\mathrm{SiO} 2$ & 60.79 & 1.10 \\
$\mathrm{~K} 2 \mathrm{O}$ & 1.39 & 15.1 \\
$\mathrm{CaO}$ & 1.37 & 0.02 \\
$\mathrm{MnO}$ & 0.08 & 1.57 \\
$\mathrm{Fe} 2 \mathrm{O} 3$ & 6.13 & 8.75 \\
$\mathrm{Na} 2 \mathrm{O}$ & 0.16 & 0.49 \\
$\mathrm{MgO}$ & 1.17 & \\
\hline
\end{tabular}

Table 2: Properties of the Natural Soil before modification

\begin{tabular}{|l|l|}
\hline Natural moisture content $(\%)$ & 24.4 \\
\hline Liquid limit $(\%)$ & 65.5 \\
\hline Plastic limit $(\%)$ & 34.9 \\
\hline Plasticity index (\%) & 30.6 \\
\hline Linear shrinkage $(\%)$ & 14.4 \\
\hline Free swell $(\%)$ & 73.0 \\
\hline Specific gravity & 2.65 \\
\hline Percentage passing No. 200 sieve & 80.2 \\
\hline Percentage Sand fraction & 74 \\
\hline Percentage Silt fraction & 16 \\
\hline Percentage Clay fraction & 10 \\
\hline Activity & 3.06 \\
\hline Maximum dry density SP $\left(\mathrm{Mg} / \mathrm{m}^{3}\right)$ & 1.4 \\
\hline Maximum dry density MP $\left(\mathrm{Mg} / \mathrm{m}^{3}\right)$ & 1.51 \\
\hline Optimum moisture content SP $(\%)$ & 27.7 \\
\hline Optimum moisture content MP $(\%)$ & 25.0 \\
\hline Unconfined compressive strength using SP $\left(\mathrm{kN} / \mathrm{m}^{2}\right)$ & 190 \\
\hline Unconfined compressive strength using MP $\left(\mathrm{kN} / \mathrm{m}^{2}\right)$ & 274 \\
\hline Soaked California bearing ratio using SP $(\%)$ & 9 \\
\hline Soaked California bearing ratio using MP $(\%)$ & 11 \\
\hline Un-Soaked California bearing ratio using SP $(\%)$ & 11 \\
\hline Un-Soaked California bearing ratio using MP $(\%)$ & 14 \\
\hline Colour & Light grey \\
\hline AASHTO classification & A-7-5(23) \\
\hline Group Index & 23 \\
\hline USCS classification & $\mathrm{CH}$ \\
\hline
\end{tabular}

Table 3: Compaction Energies Used

\begin{tabular}{|l|ll|l|l|l|l|l|l|}
\hline $\begin{array}{l}\text { Compactive } \\
\text { Effort }\end{array}$ & $\begin{array}{l}\text { Volume of } \\
\text { Mould }\left(\mathrm{cm}^{3}\right)\end{array}$ & $\begin{array}{l}\text { Weight of } \\
\text { Rammer }(\mathrm{kg})\end{array}$ & $\begin{array}{l}\text { Height of } \\
\text { Fall }(\mathrm{cm})\end{array}$ & $\begin{array}{l}\text { Number } \\
\text { of Layers }\end{array}$ & $\begin{array}{l}\text { Number } \\
\text { of Blows }\end{array}$ & $\begin{array}{l}\text { Mechanical } \\
\text { Energy }(\mathrm{j})\end{array}$ & $\begin{array}{l}\text { Work Done } \\
\left(\mathrm{Kj} / \mathrm{m}^{3}\right)\end{array}$ \\
\hline SP & 1000 & 2.5 & 30.48 & 3 & 27 & 595.958 & 595.958 \\
MP & 1000 & 4.5 & 45.72 & 5 & 27 & 2681.809 & 2681.809 \\
\hline
\end{tabular}

\section{Compaction characteristics}

On addition of WG to the soil/OPC mixture, an increase in MDD was observed with WG content. The increase in MDD was attributed to the formation of new compounds, increase in surface area of particles at higher dosage of OPC/WG blend, as well as improved workability of the soil due to the increase in the alkaline activity in the mixture and the desiccating property of WG. Figure 1 shows the effects of OPC/WG blend on the MDD of the soil. Also, the addition of water causes the bulking phenomenon in the stabilized soil. The fine cement particles influenced the reactivity of WG with the soil-cement blend, as such the soil-cement interaction resulted in the cementitious products and it gained strength. This trend is in order and agrees with Arabani et al. (2012) who reported that increase in MDD is due to the basic fact that soil-cement mix might have difference in specific gravity than the original soil

The variation of MDD with WG content for the MP compaction energy is depicted in Figure 2. An increase in compactive effort is a function of MDD, which agreed with Daniel (1993) and Abichou et al., (2000) that indicated an increase in MDD with attendant decrease in OMC for soils compacted at the energy levels of Modified Proctor, Standard Proctor and Reduced Proctor. Similarly, findings of Osinubi (1998b) showed that increase in compactive effort for lateritic soil resulted in an increase in the MDD and a decrease in the OMC. This may be attributable to the poor ability of WG to absorb moisture, and/or due to high bulk densities of the 
additive present in the cementitious compounds (C-S-H and $\mathrm{C}-\mathrm{A}-\mathrm{H})$ as well as the variation in mechanical energy applied in compacting the soil.

The variations of OMC for the two compactive efforts are shown in Figures 3 and 4. The OMC decreased with increase in OPC/WG blend for both compactive efforts. It could be that the OPC/WG dosage increased the surface area of soil particles due to the alkali $\left(\mathrm{Na}_{2} \mathrm{O}\right)$ content of WG in the formation of calcium silicate hydrates (C-S-H) for strength development of the treated soil, Khmiri et al. (2013).

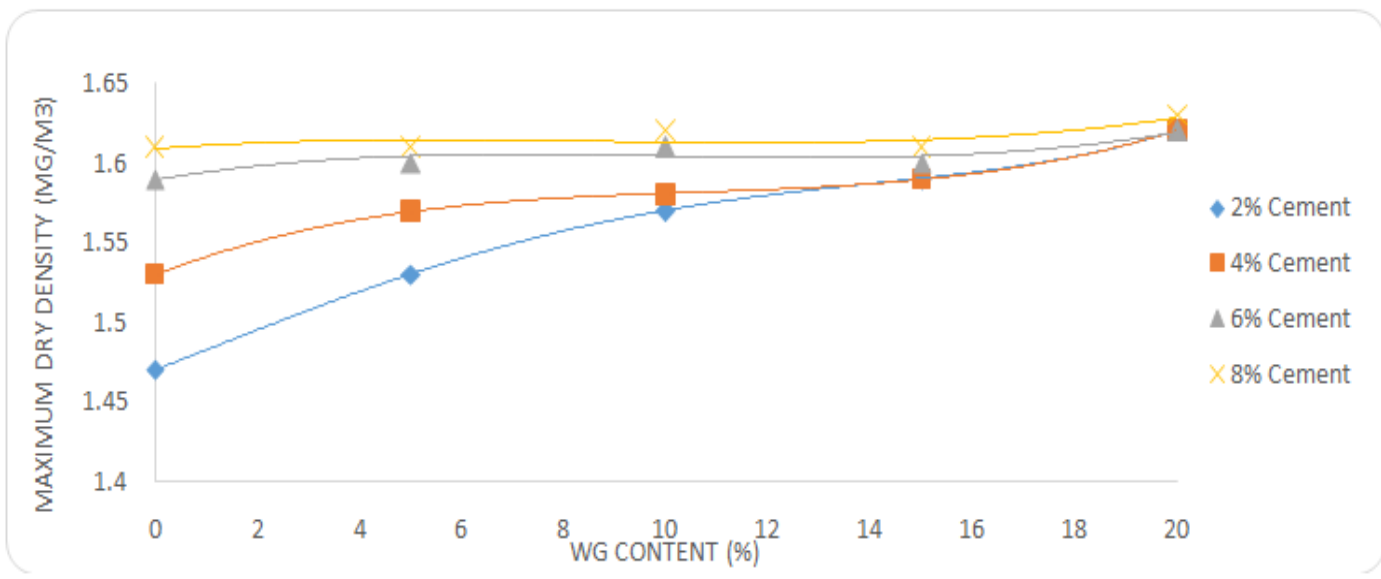

Figure 1: Variation of MDD of BCS- OPC mixture with WG content (SP compaction).

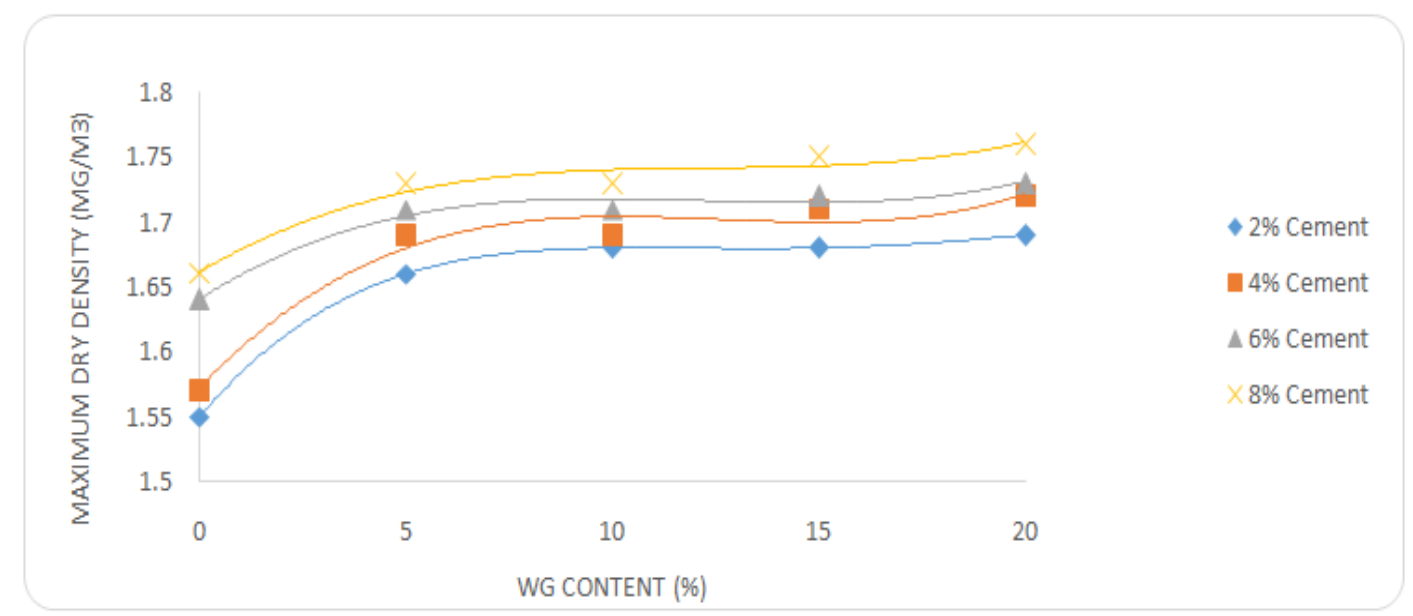

Figure 2: Variation of MDD of BCS- OPC mixture with WG content (MP compaction).

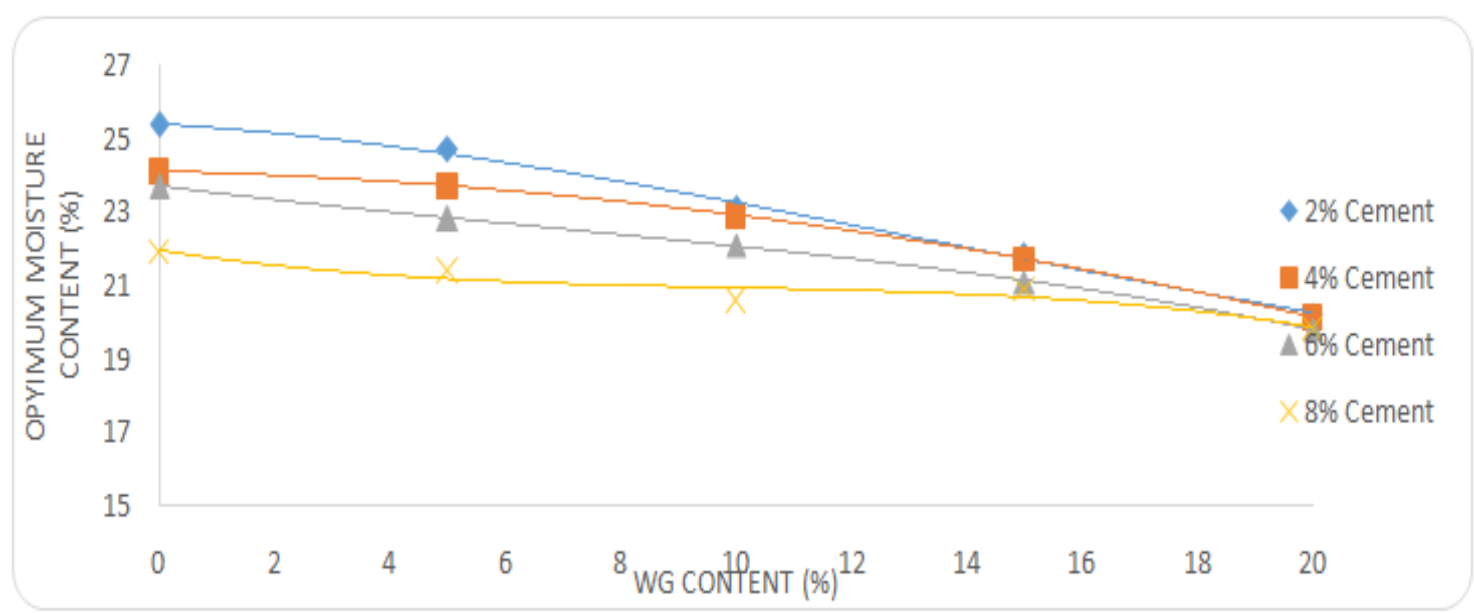

Figure 3: Variation of OMC of BCS- OPC mixture with WG content (SP compaction). 


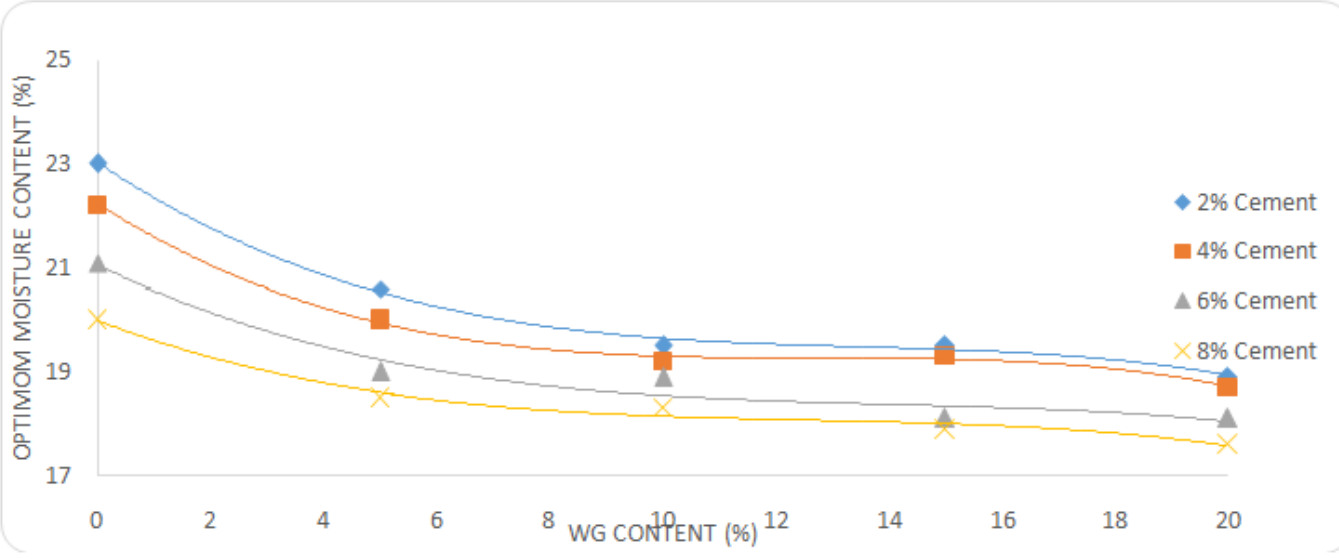

Figure 4: Variation of OMC of BCS- OPC mixture with WG content (MP compaction).

\section{Unconfined Compressive Strength}

The variation of UCS with various percentages of OPC / WG blend after compacting the specimens at OMC for 7 days using SP and MP compaction energies showed that compressive strength improved significantly after 7 days of curing. However, the peak 7-day UCS value of $1152 \mathrm{kN} / \mathrm{m}^{2}$ was recorded at $8 \%$ OPC / 20\% WG blend using the SP, while the UCS value of $1568 \mathrm{kN} / \mathrm{m}^{2}$ was obtained at $8 \%$ OPC/20\% WG using the MP compactive effort; as shown in figures 5 and 6 . These value falls short of $1710 \mathrm{kN} / \mathrm{m}^{2}$ specified by TRRL (1977) for base materials stabilization using OPC. The influence of compactive effort on the compressive strength of the 7 days cured specimens is well pronounced for each of the blend tested.

The variations of UCS for the samples cured for a period of 14 days using the two compaction energy levels are shown in Figures 7 and 8. The influence of WG admixture on the compressive strength has a longterm effect which may be attributed the slow pozzolanic chemical reaction with WG and calcium hydroxide $(\mathrm{CH})$ of cement when compared with OPC hydration. Dyer and Dhir (2001) reported that CH continuously decreased with increase WG replacement in concrete as the $\mathrm{CH}$ is consumed in the pozzolanic reaction of WG. This agreed with the assertion.

The UCS value of $1257 \mathrm{kN} / \mathrm{m}^{2}$ obtained for a combination of $8 \%$ OPC/10\% WG using the SP compaction effort was noticeably higher than the UCS values obtained for "OPC alone" treated specimens. It could therefore be inferred that the compressive strength increased linearly by fixing the OPC content and varying WG content from 5-20\%. The increase in the compressive strength may be attributable to the concentration of OPC in this range, which reduces plasticity, thereby improving cementatious properties of the soil. It is evident that the OPC/WG content, curing age, as well as the rise in the $\mathrm{pH}$ level of the soil gives rise the strength development of the specimens. The MP compactive effort resulted to higher UCS values than the specimens compacted using the SP compactive effort. This has been confirmed by Mateous (1964) who reported that increased compactive effort (from Standard Proctor to Modified Proctor) influences the strength of stabilized soil by $200 \%$ for both 7 and 28 days curing period.

The specimens compacted using the SP and MP compaction cured for 28 days shown in figures 9 and 10, respectively. The results illustrated that at 4, 6 and $8 \%$ OPC the compressive strength decreased with higher dosage of WG admixture. However, at $2 \%$ OPC content the strength increase with higher concentration of WG in agreement with Ingles and Metcalf (1972). The higher strength archived with the MP compactive effort may be due to the closer orientation of adjacent particles. The SP and MP compactive efforts yielded the highest compressive strength at $8 \%$ OPC / 5\% WG and at $8 \%$ OPC / 20\% WG blend in each case. This may be due to pozzolanic reaction, which progressively enhances the strength of the treated soil. The development of high UCS values at the 28-day curing period is attributed to the effect of OPC which promote the production of alkaline compounds that increases the $\mathrm{pH}$ value of the soil and promote the self-hardening Characteristics of the WG admixture.

By comparing the 28 days strength with those obtained at 7 and 14 days, it is obvious that the lower values obtained at 7 and 14 days were as a result of premature failure of the specimens (splitting of ends and spalling of the surface). Also, Wartman et al. (2004) suggested that the impact of WG on strength of fine grained soils may be delayed until WG particles cease floating in the fine grained matrix and develop particle to particle interactions which subsequently dominate the strength behavior, with the presence of OPC, glass powder (finer than $<0.300 \mathrm{~mm}$ and below) can act like a pozzolanic material adjacent cement Shayan and Xu (2004), as such, an increase in strength is expected. Also, this can be attributed to the trend of increasing strength with higher compaction energy as reported by Eberemu (2012). 


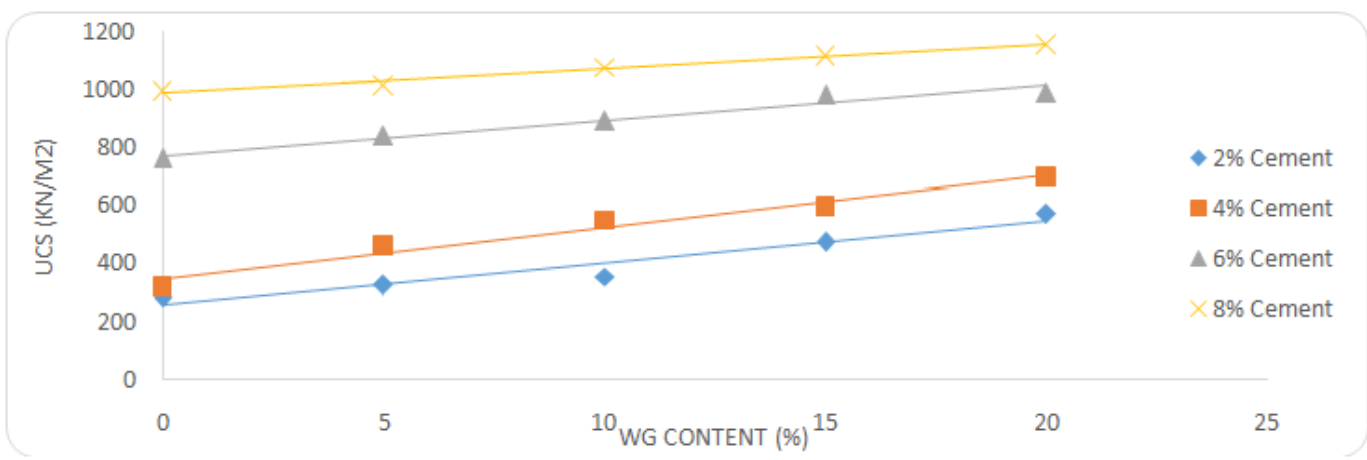

Figure 5: Variation of UCS (7days curing period) of BCS- OPC mixture with WG content (SP compaction).

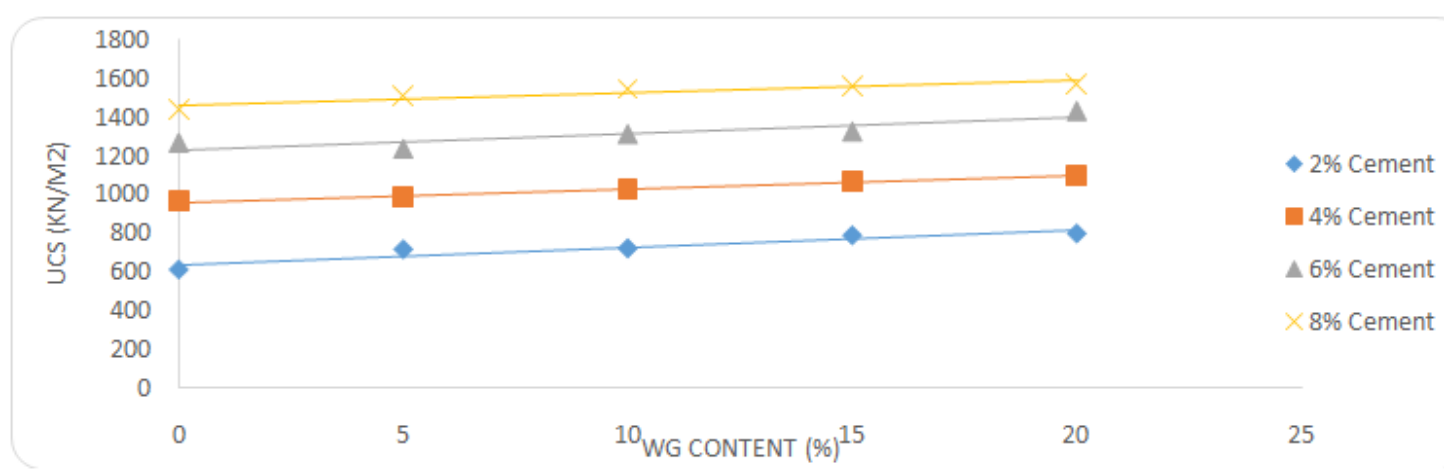

Figure 6: Variation of UCS (7days curing period) of BCS- OPC mixture with WG content (MP compaction).

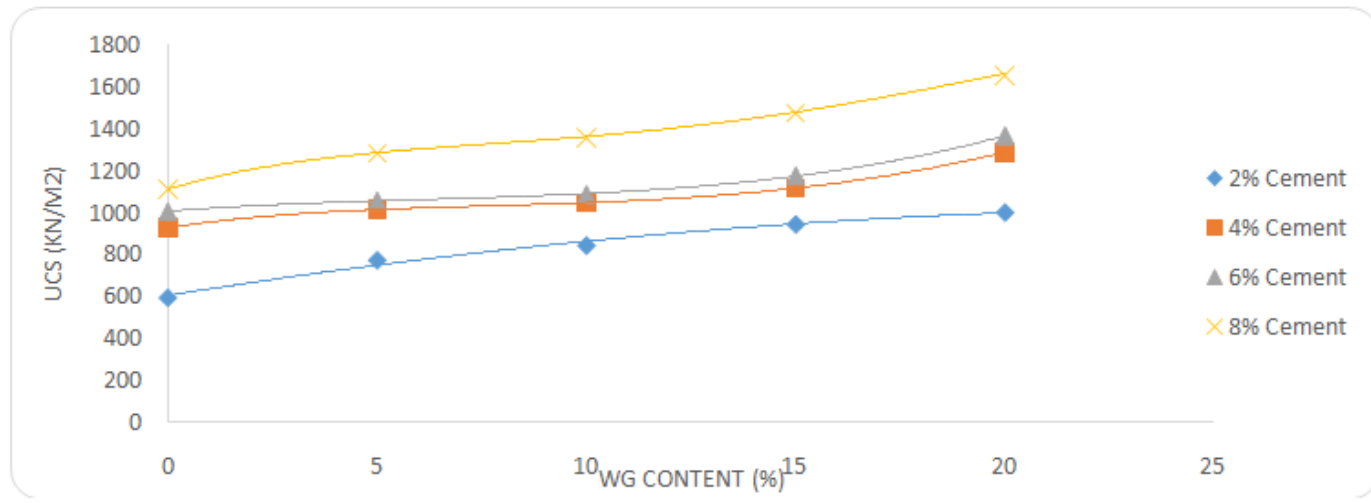

Figure 7: Variation of UCS (14days curing period) of BCS- OPC mixture with WG content (SP compaction).

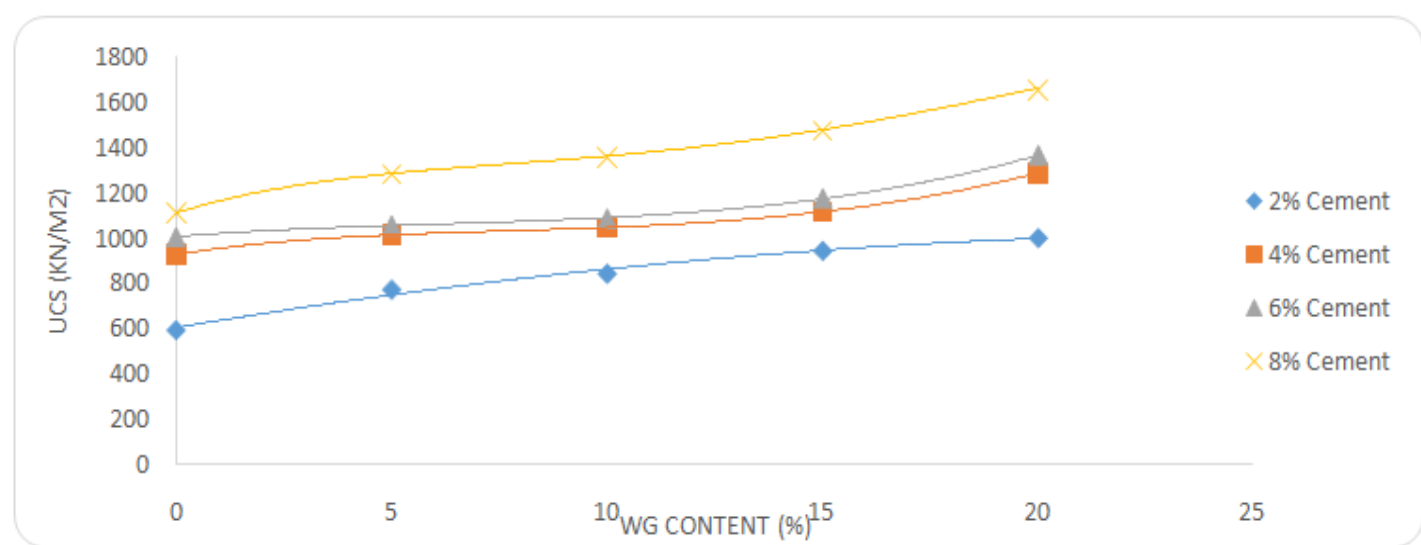

Figure 8: Variation of UCS (14days curing period) of BCS- OPC mixture with WG content (MP compaction). 


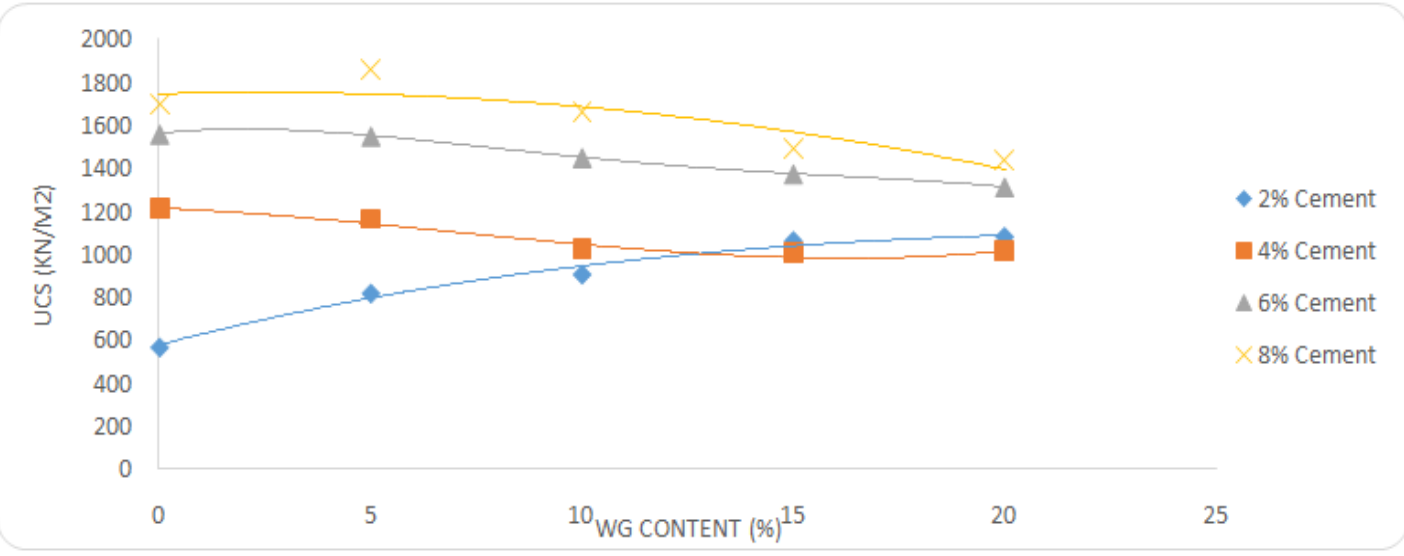

Figure 9: Variation of UCS (28days curing period) of BCS- OPC mixture with WG content (SP compaction).

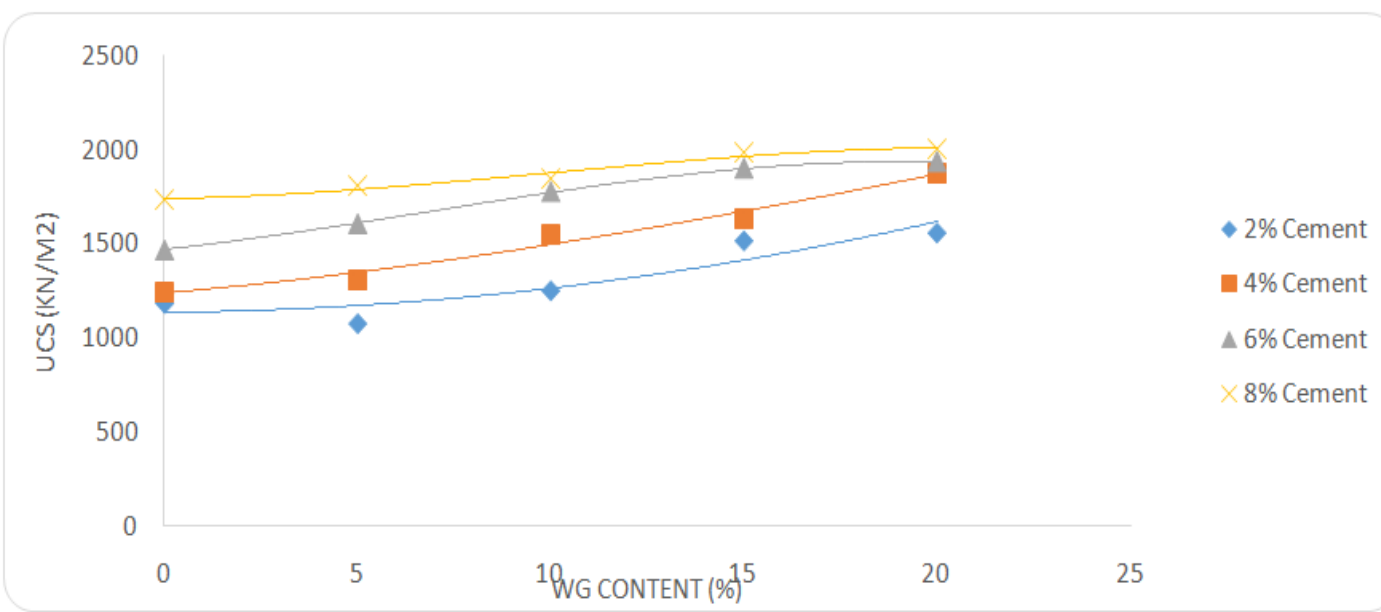

Figure 10: Variation of UCS (28days curing period) of BCS- OPC mixture with WG content (MP compaction).

\section{Durability of the UCS specimens}

The resistance to loss in strength was determined by immersion in water of the 7 days wax cured specimens (after de-waxing top and bottom) for another 7 days to simulate some of the worst conditions the stabilized soil may be subjected in the field. Specimens treated with a combination of $8 \%$ OPC $/ 20 \%$ WG for MP and $8 \%$ OPC $/ 15 \%$ WG for SP yielded $45 \%$ resistance to loss in strength (i.e. 55\% loss in strength) and $17 \%$ resistance to loss in strength (i.e. $83 \%$ loss in strength), respectively. These values are more than the maximum $20 \%$ allowable loss in strength for the conventional 7-days curing and 4 days soaking period suggested by (Ola 1974). Figures 11 and 12 show the variation of soaked - UCS specimens with SP and MP compactive efforts Variation of Resistance to loss in Strength of BCS- OPC mixture with WG content for SP and MP effort respectively.

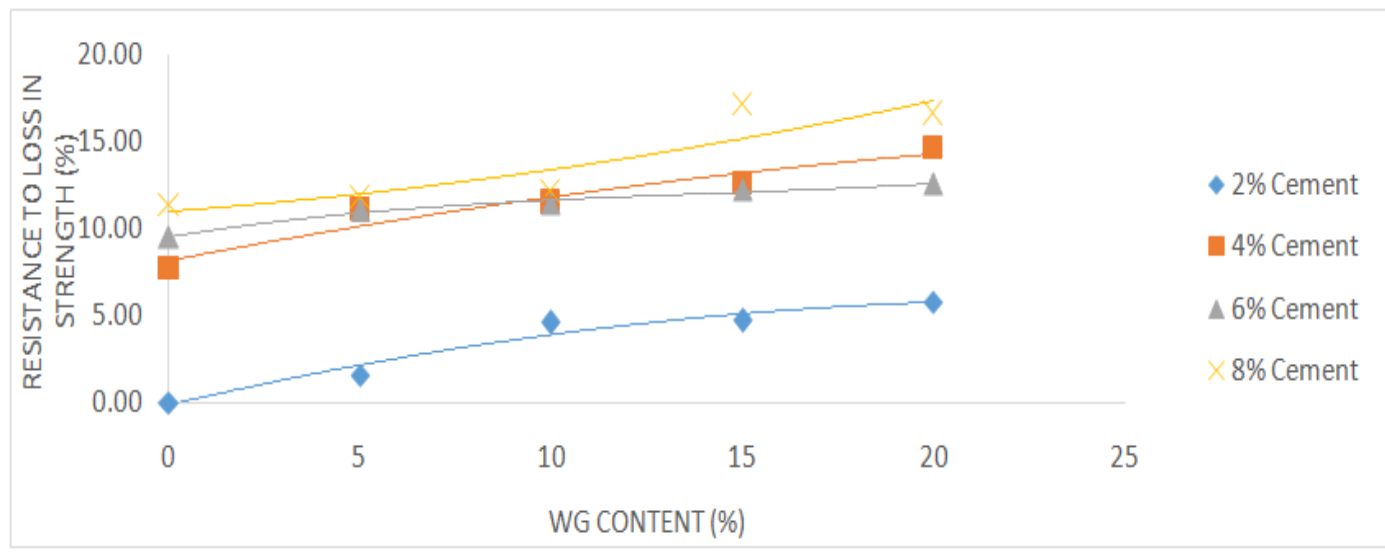

Figure 11: Variation of Resistance to loss in Strength of BCS- OPC mixture with WG content (SP compaction). 


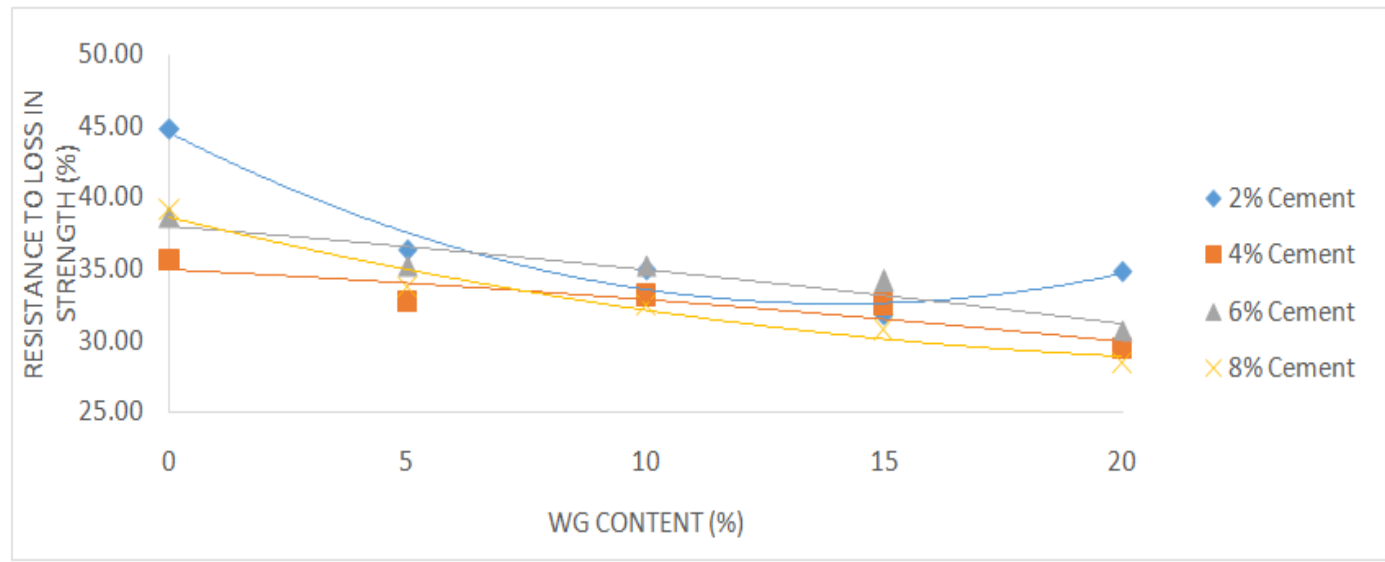

Figure 12: Variation of Resistance to loss in Strength of BCS- OPC mixture with WG content (MP compaction).

\section{California Bearing Ratio}

Figures 13 and 14 shows the variation of un-soaked CBR with various percentages of OPC/WG blend using the SP and MP compactive effort. The variation of un-soaked CBR with various percentages of OPC/WG blend using the MP compactive effort showed slightly higher values than for the SP compactive effort.

The CBR value of the specimen treated with OPC only increased with increase in OPC content for both the compactive efforts. With the addition of WG, the CBR value increased at higher percentage of WG. This may be attributed to the increase in the contact area and adhesion between OPC and soil by WG which will create a dense network of interconnected particles. A peak value of $63 \%$ was observed at $8 \%$ OPC/20\%WG blend, for the MP compactive effort. Similarly, an increase of about $407.5 \%$ in the CBR value was noticed when the natural soil was compacted using the SP effort and the increase occurred at $8 \%$ OPC/20\%WG blend.

It was reported by Arabani et al., (2012), in their study of cement stabilized with crushed glass sand blends that the cementitious reaction between cement and admixture took place as a primary process. The hydration of the cement was regarded as primary reaction and formed the normal hydration products that bound particles together. The increase in the CBR value may be due to the shear transfer mechanism between the soil and WG, and the improvement in the strength might be due to the pozzolanic action of WG/OPC mix. Furthermore, the peak CBR value of $39 \%$ and $37.8 \%$ achieved at the SP and MP compactive efforts, respectively, with $0 \% \mathrm{WG}$ content did not meet the $180 \%$ CBR value criterion recommended by the Nigerian General Specification (1997) for OPC stabilized soil. This is attributed to the high content of montmorillonite in the soil, which seems to negate the effectiveness of OPC.

Specimens treated with $8 \% \mathrm{OPC} /(5-20 \%) \mathrm{WG}$ and compacted with both the two energy levels meet the requirement of $30 \%$ CBR of the Nigerian General Specification (1997) for use of the soil material for subbase in roads, other mixes also met this requirement, they include $6 \%$ OPC/ (5-20\%) WG, $4 \%$ OPC /20\% WG compacted at MP energy level and 6\% OPC / (15-20\%) WG compacted at SP energy level

However, at 2, 4 and 6\% OPC with varying proportions of WG compacted with both compactive effort did not meet the requirement for good quality base or sub-base for road pavement, it however, suffices for use as a sub-grade material.

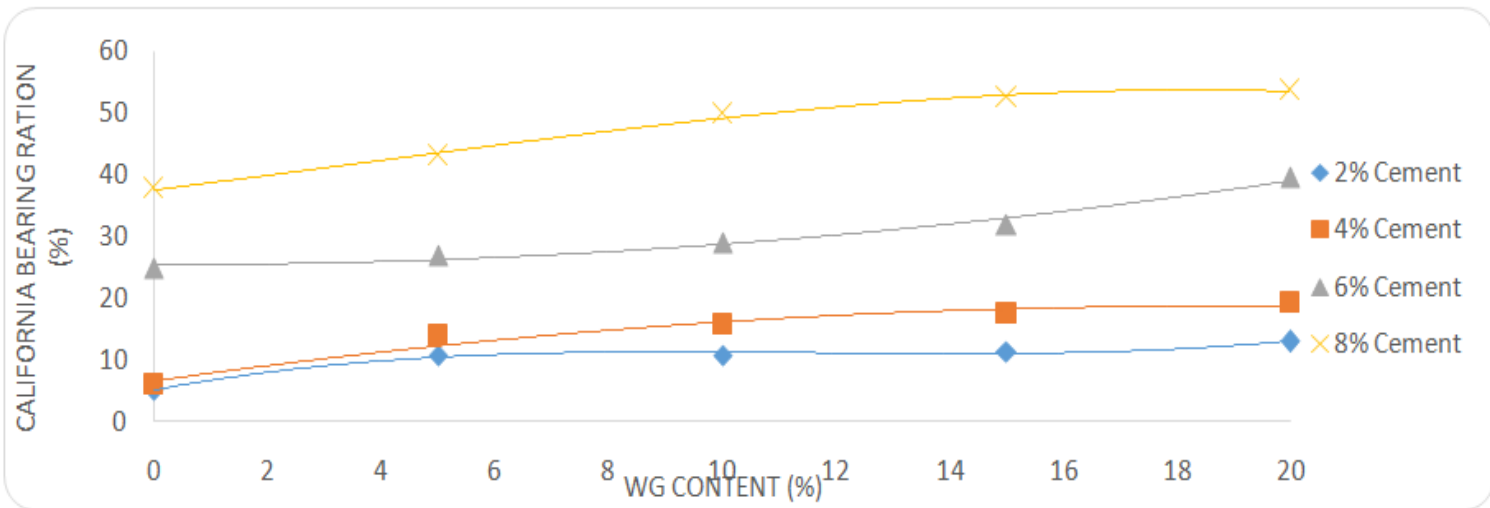

Figure 13: Variation of Un-soaked CBR of BCS- OPC mixture with WG content (SP compaction). 


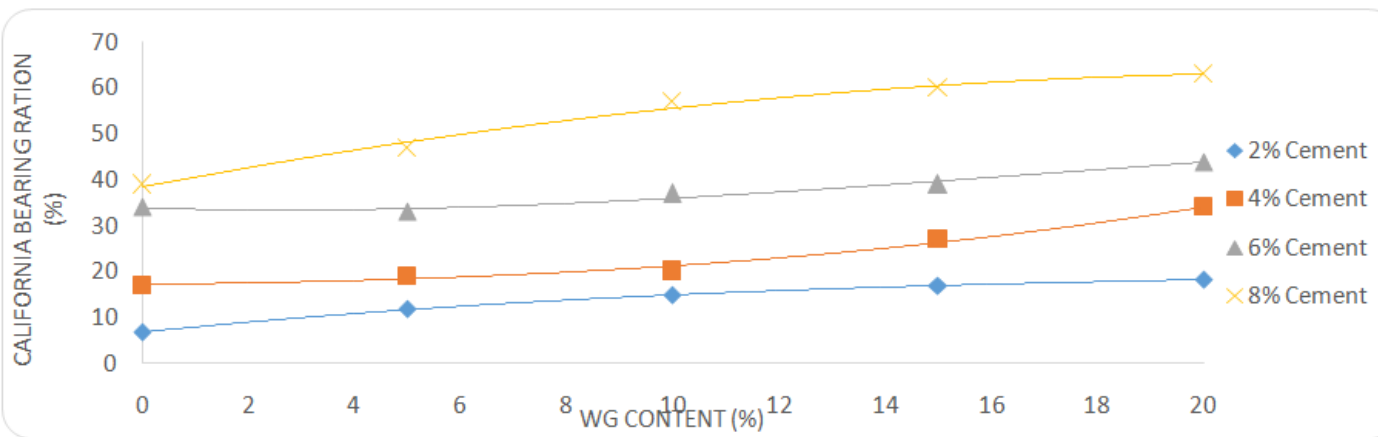

Figure 14: Variation of Un-soaked CBR of OPC stabilized BCS with WG content for MP compactive effort.

\section{Conclusion}

The natural soil falls under A-7-5(13) or CH subgroup in accordance with the AASHTO and USCS classification, respectively. Soils under these groups are of poor engineering benefit. A substantial reduction in plasticity index when compared to the untreated soil was observed, this seems to give creditability to the physiochemical reactions between the soil and OPC /WG blend.

In general, the OMC decrease with increasing OPC/WG content for both compactive efforts, with MP compactive effort yielding high MDD due to the greater energy supplied. A remarkable improvement in Unconfined Compressive Strength (UCS) was observed at $8 \%$ OPC/20\% WG treatment, yielding an average UCS value of $1152 \mathrm{kN} / \mathrm{m}^{2}$ and $1568 \mathrm{kNm}^{2}$ at 7 days curing for SP and MP compactive effort. However, none of these 7 days specimens compacted using the two energy levels for the 7 days curing met the minimum strength requirement of $1720 \mathrm{kN} / \mathrm{m}^{2}$ as specified by Road Note 31 (TRRL, 1977) for an economic range of OPC stabilization.

Higher Unconfined Compressive Strength (UCS) values were observed for both compactive efforts at 28 days curing, this seems to give creditability to the pozzolanic reaction of fine WG. Peak CBR values obtained for both energy levels met the requirements of the Nigerian General Specifications (1997) 30\% CBR criterion for sub-base and sub-grade material in light trafficked roads.

Generally, based on the above conclusions, the strength of black cotton soil depends primarily on the mineral composition, which is best manifested in the plasticity characteristics of the soil. The addition of WG resulted in the reduction of plasticity index, thus given rise to greater workability when compared to untreated clays. The results also showed that WG could be used efficiently to reduce the swell potential of expansive soils, improve the Unconfined Compressive Strength (UCS) and CBR.

\section{References}

[1]. AASHTO (1986), Standard Specifications for Transportation Materials and Methods ofSampling and Testing, $14^{\text {th }}$ edition, American Association of State Highway and Transportation Officials, Washington, D.C.

[2]. Abichou, T., Benson, C. H. and Edil, G. T. (2000). Foundry Green Sand as HydraulicBarriers Laboratory Studies. Journal of Geotechnical and Geo-environmental Engineering, ASCE, Vol. 126, No.12, pp. $1174-1183$.

[3]. Arabani, M., Sharafi, H., Habibi, M.H. and Haghshenas, E. (2012). "Laboratory evaluationof cement stabilized crushed glass-sand blends". Electronic Journal of Geotechnical Engineering (EJGE), Vol. 17, pp. 1777-1792.

[4]. Ashango, A.A. and Patra, N.R. (2014), "Static and Cyclic Properties of Clay Subgrade Stabilized with Rice Husk Ash and Portland Slag Cement", International Journal of Pavement Engineering,DOI:10.1080/10298436.2014.893323

[5]. ASTM (1992), "Annual Book of Standards." Vol.04. 08, American Society for Testing and Materials,Philadelphia.

[6]. BS 1377 (1990). Methods of Testing Soils for Civil Engineering Purposes. British Standard Specification. London.

[7]. BS 1924 (1990). Methods of Tests for Stabilized Soils. British Standard Specification. London.

[8]. $\quad$ Chen, F.H. (1988). "Foundations on Expansive Soils." Developments in Geotechnical Engineering. Vol.54, Amsterdam: Elsevier Science Publishing.

[9]. Daniel, D. E. (1993). Geotechnical Practice for Waste Disposal. Chapman and Hall, London, 683p.

[10]. Dyer, T.D. and Dhir, R.K. (2001)."Chemical Reactions of Glass Cullet used as Cement Component" Journal of Materials in Civil Engineering, 13(6), pp. 412-417.

[11]. Eberemu, A. O., Amadi, A.A, and Lawal M, (2012) "The Geotechnical properties of black cotton soil treated with crushed glass cullet." Nigerian Journal of Technological Research

[12]. Ikara, I.A., Kundiri, A.M. and Mohammed, A (2015)" Effects of Waste Glass (WG) on the Strength Characteristics ofCement Stabilized Expansive Soil" American Journal of Engineering Research (AJER)Vol. 4, Issue-11, pp. 33-41

[13]. Ingles, O.G. and Metcalf, J. B. (1972). Soil stabilization principles and practice. Burtterworths, Sydney, 103-144.

[14]. Jefferson, I. and Rogers, C. D. F. (1998). Liquid Limit and the Temperature Sensitivity of Clays. Engineering Geology, Vol. 4, pp. $95-109$.

[15]. Joel, M. and Agbede, I. (2011) "Mechanical-Cement stabilization of laterite for use as flexible pavement material, "Journal of Material in Civil Engineering, Vol.23, No.2, pp.146-152.

[16]. Khmiri, A., Chaabouni, M. and Samet, B., (2013).” Chemical behaviour of ground waste glass when used as partial cement replacement in mortars". Construction andbuilding materials, 44, pp. 74-80.

[17]. Mateous, M. (1964). "Soil-lime research at Iowa State University" Proceedings of ASCE, Journal of soil mech. Foundation. Div. 90, SM2, pp. 127-153. 
[18]. Moses G. and Osinubi K. J. (2013). "Influence of Compactive Efforts on Cement-Bagasse Ash Treatment of Expansive Black Cotton Soil." World Academy of Science, Engineering and Technology, Pp. 1559 - 1566.

[19]. NBRRI, (1983). Engineering properties of black cotton soil of Nigeria and related pavement design. Nigerian building and road research institute, research paper No. 1-20.

[20]. Ola, S. A. (1974) "Need for estimated cement requirement for stabilizing lateritic soil."J.Transport Div., ASCE,Vol. 17, No 8, pp. 379-388.

[21]. Osinubi1, K. J., Oyelakin, M. A. and Eberemu, A. O., (2011). Improvement of Black Cotton Soil with Ordinary Portland cement Locust Bean Waste Ash Blend. Electronic Journal of Geotechnical Engineering, Vol. 16, pp. 619-627.

[22]. Osinubi, K. J. and Nwaiwu, C. M. O. (2005). Hydraulic Conductivity of Compacted Lateritic Soil. Journal of Geotechnical and Geo-environmental Engineering, ASCE, Vol.131, No.8, pp1034 - 1041.

[23]. Osinubi, K.J. (1998b). Permeability of lime treated lateritic soil. Journal of Transportation Engineering, ASCE, Vol. 124, No. 5, pp. 465-469.

[24]. Osinubi,K.J. (1999). Evaluation of admixture stabilization of Nigerian black cotton soil. Nigerian society of Engineers technical transactions, Vol.34, No. 3, pp.88-96.

[25]. Shayan, A., Xu, A. (2004). Value-added utilization of waste glass in concrete. Cement and Concrete Research 34 (1), 81-89.

[26]. TRRL (1977). A Guide to the structural design of bitumen-surface roads in tropical and subtropical countries, road note 13, Transport and research laboratory, H.M.S.O., London.

[27]. Wartman, J., Grubb, D. G. \& Strenk, P. (2004). Engineering properties of crushed glass soil blends. Geotechnical engineering for transportation projects. ASCE, New York, pp. 732-739. 